\title{
Reaction norms for metamorphic traits in natterjack toads to larval density and pond duration
}

\author{
R. Reques ${ }^{1}$ and M. Tejedo ${ }^{2.3, *}$ \\ 'Departamento de Biología Animal, Facultad de Ciencias Biológicas, Universidad \\ de Córdoba, E-14005 Córdoba, Spain \\ ${ }^{2}$ Departamento de Ecología Evolutiva, Museo Nacional de Ciencias Naturales, \\ C.S.I.C., José Gutiérrez Abascal 2, E-28006 Madrid, Spain \\ ${ }^{3}$ Present address: Estación Biológica de Doñana, CSIC, Pabellón del Perú, Avda. \\ de Maria Luisa, s/n E-41013 Sevilla, Spain,e-mail: tejedo@ebd03.ebd.csic.es
}

Key words: Phenotypic plasticity; reaction norm; genetic correlations; metamorphosis, Bufo calamita.

\begin{abstract}
The evolution of environmentally-induced changes in phenotype or reaction norm implies both the existence at some time of genetic variation within a population for that plasticity measured by the presence of genotype $\times$ environment interaction $(G \times E)$, and that phenotypic variation affects fitness. Otherwise, the genetic structure of polygenic traits may restrict the evolution of the reaction norm by the lack of independent evolution of a given trait in different environments or by genetic trade-offs with other traits that affect fitness. In this paper, we analyze the existence of $G \times E$ in metamorphic traits to two environmental factors, larval density and pond duration in a factorial experiment with Bufo calamita tadpoles in semi-natural conditions and in the laboratory.

Results showed no plastic temporal response in metamorphosis to pond durability at low larval density. The rank of genotypes did not change across different hydroperiods, implying a high genetic correlation that may constrain the evolution of the reaction norm. At high larval density a significant $G \times E$ interaction was found, suggesting the potential for the evolution of the reaction norm. A sibship (\#1) attained the presumed "optimal" reaction norm by accelerating developmental rate in short duration ponds and delaying it in longer ponds. This could be translated in fitness by an increment in metamorphic survival and size at metamorphosis in short and long ponds respectively with respect to non-plastic sibships.
\end{abstract}

\footnotetext{
* Author for correspondence.
} 
However, genetic variability for plasticity suggests that optimal reaction norm for developmental rates may be variable and hard to achieve in the heterogeneous pond environment.

Mass at metamorphosis was not plastic across different pond durations but decreased at high larval density. Significant adaptive plasticity for growth rates appeared in environments that differed drastically in level of crowding conditions, both in the field and in the laboratory. The fact that survival of juveniles metamorphosed at high density ponds was a monotonic function of metamorphic we. implies that response to selection may occur in this population of natterjacks and that genetic variability in plasticity may be a reliable mechanism maintaining adaptuc genetic variation in growth rates in the highly variable pond environment.

\section{Introduction}

A central point in evolutionary ecology is the mode of evolution of organisms in heterogeneous environments in which important environmental characteristics vary over space or time. Selection will favor, by stabilizing or directional selection, an optimal trait value with the highest fitness in stable or slightly varying environments. However, in environments that widely vary on a spatial or temporal scale, fitness will depend on the environment and the outcome of evolution is not clear. The alternatives are either the preservation of multiple genotypes that express a fixed phenotype with maximal fitness to particular environments (specialists) or the selection of at genotype with an array of phenotypes across environments that matches the most fit phenotype for that particular environment (generalists). This matching maly involve a phenotypic change across environments (phenotypic plas(Icity) (Via and Lande, 1985; van Tienderen, 1991). The role of phenotypic plastlcity in the context of phenotypic evolution in variable environments has recesed much attention in the last decade (e.g., Schlichting, 1986; Via, 1987, 1994; Schemer, 1993: Travis. 1994). For adaptive plasticity to evolve in response to heterogeneous selection, genotypes within populations must vary in reaction norms, that is. in phenotypic response to a given range of environments. This genetic barlation in phenotypic plasticity is known as genotype $\times$ environment interaction $((; \times E)$ (Via and Lande. 1985; (Gomulkicwicz and Kirkpatrick, 1992). The selection of an adaptive reaction norm would imply a priori the assumption that a plastic reaction norm does not incur a cost in fitness when compared with a non-plastic reaction norm. However, this assumption hinges on the optimistic view that selection acts without any constraint imposed by the development system and the genetics governing the development of the target traits (Stearns and Koella. 1986). Lack of genetic varıability within one or both environments or lack of independence between different character states may limit the evolution of an adaptive reaction norm (Falconer, 1952; Yamada, 1962: Via and Lande, 1985, 1987; Via, 1987. Via et al.. 1995). Another genetic constraint may be imposed by the existence of a genetic trade-off that limits the expression of eorrelated characters (e.g., if there is genetic dependence of fitness related traits. the evolution of adaptive plasticity 
may be limited) (Scheiner and Goodnight, 1984; Blouin, 1992; Semlitsch, 1993; Newman, 1994a).

Temporary ponds used by amphibians during their larval phase are paradigmatic examples of habitats varying both temporally and spatially (Pechmann et al., 1991; Newman, 1989, 1992; Tejedo and Reques, 1994). This transitional period in the amphibian life cycle, with growth and development but not reproduction, is governed by important biotic and abiotic regulatory factors. Pond duration, temperature, larval density, predation, and nutrient availability are major sources of environmental variability that may shape the larval phase by affecting traits such as developmental rate and metamorphic size (Wilbur, 1980, 1987; Semlitsch and Wilbur, 1988; Newman, 1989, 1994a; Tejedo and Reques, 1994). The duration of the pond is clearly a potential cause of mortality for amphibians (Shoop, 1974; Smith, 1983; Newman, 1989; Tejedo and Reques, 1994). Larval density interactions govern development and growth, determining a lengthening of larval period and reducing size at transformation, with strong implications for fitness (Newman, 1989; Berven, 1990; Scott, 1994). Because the level of intraspecific competition may change dramatically across and within years (Newman, 1994b; Tejedo, 1992a; Tejedo and Reques, 1994) we can predict that selection would favor the existence of genetic variability in the susceptibility to intra-interspecific competition, although selection can also lead to genetic uniformity if an appropriate optimal plastic response is achieved (C. D. Schlichting, pers. comm.). However, very few attempts have been made to analyze genetic variability in traits associated with fitness and in the reaction norm to intraspecific competition in amphibians and other organisms (Travis, 1983a; Shaw, 1986; Mazer and Schick, 1991; Thomas and Bazzaz, 1993).

An adaptive response to pond duration is plasticity in the phenotypic expression of the developmental rate. Because of the unpredictability of the environment a fixed rate, might be not selected because there would be no optimal size or developmental time and the optimal phenotype would depend on pond duration (Newman, 1988). Short durations would favor high developmental rates to avoid risk of mortality by desiccation. On the other hand, when the duration of pond lengthens, larger sizes at metamorphosis would be predicted (Wilbur and Collins, 1973; Newman, 1988). Therefore, the adaptive plasticity hypothesis will require both a negative correlation of age at metamorphosis with metamorphic success in short duration ponds, and a positive correlation of age with size at metamorphosis in long-lived ponds. The optimal response of timing to metamorphosis would probably be a more complex non-linear function which balances weight gain against the probability of not surviving later conditions (C. C. Schlichting, pers. comm.). This prediction implies that adaptive plasticity in developmental time would create antagonistic pleiotropy between metamorphic traits with respect to fitness for species breeding in temporary ponds.

The natterjack toad, Bufo calamita, is a species which breeds in temporary ponds, that may experience high variability in both pond duration and larval density, and where catastrophic mortalities due to premature pond drought, are common events (Banks and Beebee, 1988; Sinsch, 1992; Tejedo and Reques, 1994). In the temporary 
ponds where natterjacks breed an increase in pond duration is not necessarily translated into superior metamorphic success, due to associated increases in larval density and crowding that lengthen the larval period (Tejedo and Reques, 1994). In this sense, both environmental factors are interrelated, and their effects on metamorphic success may not be additive, representing an ecological tradeoff that may have important implications for fitness. Moreover, the pulsed pattern during the reproductive season and opportunistic breeding in very shallow ponds considerably increase the range and heterogeneity in both pond hydroperiods and larval density levels that are experienced by natterjack larvae (Tejedo, 1992a; Tejedo and Reques, 1994).

In this paper we analyze experimentally the hypothesis of adaptive plasticity in metamorphic traits of natterjacks to heterogeneous pond environments that differ both in duration and larval density. To address this question, we examined the reaction norm of five different sibships raised in artificial ponds under field conditions, to variable pond duration and larval density and to variable density in the laboratory, and determined Genotype $\times$ Environment interactions, and genetic and phenotypic correlations. Finally, the relationships between metamorphic size and juvenile growth rates and survival were analyzed.

\section{Material and methods}

\section{Experimental design and treatments}

\section{Laboratory experiment}

Samples of eggs from each of the five sibships were brought to the laboratory approximately 12 hours after fertilization and their diameter measured to the nearest $0.01 \mathrm{~mm}$. To determine genetic variability within and across densities in the laboratory we raised each sibship until metamorphosis in two different densities, two (low) and eight larvae (high). This defined 10 treatments in a two-factor $5 \times 2$ factorial design that was replicated in four complete spatial blocks. Treatments were randomized within each block. Tadpoles were reared in Petri dishes $(15 \mathrm{~cm}$ dia, and $250 \mathrm{ml}$ of dechlorinated tap water). The established density was similar to pond bottom surface density tested in field conditions (high: $453 \mathrm{larvae} / \mathrm{m}^{2}$; low: $113 \mathrm{larvae} / \mathrm{m}^{2}$ ). Once sibships reached Gosner's stage 25 (Gosner, 1960), we haphazardly selected 40 tadpoles from each of the sibships. Afterwards, tadpoles were randomly assigned to either high or low densities. Each dish initially received $30 \mathrm{mg}$ of Purina rabbit chow that was increased to $70 \mathrm{mg}$ the third week after the onset of the experiment, and water was changed every other day. Tadpoles were kept with natural light and air temperature oscillated between $22-25^{\circ} \mathrm{C}$.

\section{Field experiment}

To determine the genetic variability in metamorphic traits and plasticity as a function of differing larval densities and pond durations, we designed an experiment with all possible combinations of three factors: two tadpole densities, two 
pond durations and five different sibships (20 treatments in a $2 \times 2 \times 5$ factorial design). Each treatment was replicated in three spatial blocks. We randomized each treatment within the blocks. During the first week of March 1993, artificial ponds were placed in a fenced field adjacent to the Toba breeding area (see description elsewhere, Tejedo, 1992a; Tejedo and Reques, 1994). We established 60 square plastic boxes $0.50 \times 0.37 \times 0.28 \mathrm{~m}$ as artificial ponds. On 10th March we filled containers with water from a nearby well. An equal amount of detritus and sand $(1 \mathrm{~kg})$ and water (11) from a natural pond were added to each container. These were not covered, but potential predators were rarely observed (e.g., Dystiscus, Notonecta); these were immediately removed from the ponds. On 30th April, a storm triggered a burst of natterjack reproduction and five different clutches were randomly selected the next morning and isolated in different containers. These clutches represented five different families because females only lay a single clutch per season and males are able to amplex only a single female per night, due to the long duration of amplexus (Tejedo, 1992b). On 10th May, tadpoles had reached Gosner's stage 25. At this point, we randomly collected tadpoles from each family container and assigned 20 tadpoles to those treatments of low density and 80 tadpoles to those of high density. These values represented a density of 108 and 432 larvae $/ \mathrm{m}^{2}$ respectively, well within the estimated tadpole density during nine years of sampling (which ranged between 68-553 larvae $/ \mathrm{m}^{2}$ ) (Tejedo and Reques, 1994). Pond duration treatment consisted of two levels: short and long duration ponds which were differentiated by their initial depth. A long duration pond was set as $25 \mathrm{~cm}$ (46.21) whereas short duration ponds was set as $12 \mathrm{~cm}(22.21)$. Water in both pond treatments was allowed to evaporate; we did not control increases in treatments due to substantial precipitations especially during May. Short duration ponds dried up after 45 days on 25 th June. This duration falls within the range observed in natural ponds for that time of the season (32-65 days, Tejedo and Reques, 1994). Each container received $0.6 \mathrm{~g}$ of Purina rabbit chow (17\% proteins) every other day until the conclusion of the experiment on June 25 th.

\section{Juvenile growth and survival}

A sample of metamorphs belonging to each sibship from high density field enclosures were kept in the laboratory to analyze the genetic variability associated with juvenile growth rate. On June 19th we randomly selected ten metamorphs of each family, three days old, which were raised individually in plastic containers (31). The toads were grown for a month until 19th July. Containers were arranged into ten randomized complete blocks in the laboratory. The toads were fed ad libitum with ants (Tapinoma $\mathrm{sp}$ ) collected beside the natural pond, which were actively preyed upon by recent metamorphs. Juveniles were weighed at the start and end of the experiment. Growth rate was estimated with the expression:

$$
\text { Growth rate }=\left(\operatorname{Ln} m_{2}-\operatorname{Ln} m_{1}\right) / 30 \text { days }
$$

( $m_{2}$ and $m_{1}$, mass at the end and at the start of the experiment). 
Nonparametric regression between size at metamorphosis and survival rate of these juveniles was carried out with the cubic-spline to generate selection surfaces GLMS (Schluter, 1988). Standard errors for the spline were calculated by bootstrapping the original data 100 times.

\section{Response variables and statistical analysis}

After the first metamorph was discovered, ponds were checked daily and all metamorphs found were collected and carried to the laboratory where they were kept in plastic Petri dishes $(15 \mathrm{~cm}$ dia) with sand and $1 \mathrm{~mm}$ of water until tail resorption was completed. Two metamorphic variables were measured: (1) time to metamorphosis, or period elapsed since the start of the experiment until the first forelimb protrusion (Gosner stage 42); (2) mass at metamorphosis, measured at tail resorption (Gosner stage 46) to the nearest $0.1 \mathrm{mg}$. This estimate best reflects body size at metamorphosis (Travis, 1980). Analyses of time to and mass at metamorphosis were based on the first $30 \%$ of metamorphs from each pond. These individuals represented the lower tail of time to metamorphosis distribution and allowed comparison of age and size at metamorphosis between different pond durations without the expected bias in the mean of the distribution of time to metamorphosis (and in mass, if this trait exhibits a correlation with date) due to the truncation observed in short duration ponds. Survival to metamorphosis was examined as two components (Newman, 1989; Semlitsch and Reyer, 1992): (1) percentage of tadpole survival, the percentage of individuals surviving of those initially added to the ponds, and (2) percentage of metamorphosis, the percentage of surviving tadpoles that metamorphose. Data for survival were collected until 25 June when short duration ponds dried out.

The responses of tadpoles were analysed first by three-factor multivariate analysis of variance (MANOVA; all four response variables together). This was used because these responses are often correlated within populations. We performed univariate ANOVAs for all significant treatment effects yielded in the MANOVA. We used the mean of individual responses for each pond as a measure of the response for that experimental unit, to avoid the lack of independence of individual measures and thus pseudoreplication (Hurlbert, 1984). Mass at, and time to, metamorphosis were $\log _{e}$-transformed to reduce heterogeneity of variances among treatments. Survival data were angularly transformed by the arcsin square root transformation. A stochastic event, a storm on 14th May which overturned 15 containers, yielded an unbalance in our initial experimental design.

Between-environments phenotypic plasticity in metamorphic traits was analysed using two-way mixed model ANOVAs with an environmental factor (larval density or pond duration) and a sibship factor. $G \times E$ interactions indicate genetic variability for plasticity. The differences between density and pond duration were considered "fixed effects" since neither were selected at random. Different sibships were selected at random within the population and were considered a "random effect". The mixed model ANOVA provided F-tests constructed using the type Ill expected 
mean squares provided by PROC GLM in SAS (SAS Institute, Inc. 1990), (Model II in Ayres and Thomas 1990; the "SAS" model in Fry 1992). Type III SS accounts for unequal cell size and produces orthogonal tests of hypotheses (SAS Institute Inc., 1990). This gives a conservative measure of treatment effects. The evolution of the reaction norm necessarily requires the existence of genetic variability in at least one the environments (C. D. Schlichting, pers. comm.). Because the two-way ANOVAs do not provide the magnitude of genetic variability available for a response to selection within environments, we estimated it by separate one-way ANOVAs in each environment, and when sibship variability was evidenced, we examined sibship differences in mean performance by using a Tukey-Kramer HSD multiple a posteriori comparison test. Block effect was negligible and contributed little to variation in response variables, therefore it was pooled into the residual term. Due to the unbalanced nature of the data, the significance tests are considered approximations.

To further delineate the effects of $G \times E$ on the potential for phenotypic plasticity evolution in natterjack metamorphic traits, we regarded the character expressed in each particular two-environment combinations of pond duration and larval density as a pair of genetically correlated character states (Falconer, 1952; Via and Lande, 1985). The genetic correlations of time to metamorphosis and size at metamorphosis across different habitat combinations were calculated using two different approaches. Firstly, variance component correlations across environments were calculated following the methods of Fry (1992), which involve estimating variance components from the sibship main effect and the sibship component of covariance across a set of all comparisons in a two-environment ANOVA. The sibship variance component for all potential two environment combinations were estimated in PROC VARCOMP of SAS using two methods (1) the method of equating observed mean squares to expected value (TYPE1 estimate) and, (2) the method of restricted maximum likelihood (REML). Fry (1992) stated that TYPE1 estimates may be biased if the dataset is unbalanced. Also, REML estimates should be taken cautiously when there is a possibility of negative genetic correlations. Because of both negative genetic correlation across environments and the unbalanced nature of our dataset, we present both variance component methods for comparison. Secondly, we calculated the Pearson product-moment correlations based on mean full-sib families in the two environments (Method I, Eq. 2) or Via (1984). These family mean correlations are only approximations of the true genetic correlations because each variance and covariance used in their estimation contains a fraction of the within family "error" variance or covariance (Via, 1984). The family mean correlations tend to be underestimates of the true genetic correlation if compared with the less biased variance component estimate (Yamada, 1962; Fry 1992; Via and Conner, 1995), but the use of family mean correlation often allows a more powerful statistical test of whether the genetic covariance is significantly different from zero (Rausher, 1984). These correlations and the complementary two-environment ANOVAs were used to examine two different biological hypotheses: (a) Do the character states exhibit complete genetic independence? To test the hypothesis 
of complete genetic independence we examined whether cross-environmental genetic correlations differed significantly from zero. This was tested using the significance of sibship main effect in the two-environments ANOVA and was compared with the significance of family mean correlations, which tested the same hypothesis (Via and Conner, 1995); (b) Do the character states exhibit complete genetic dependence and is their evolution necessarily coupled? To test the hypothesis of complete genetic dependence we tested whether cross-environmental genetic correlations differed significantly from +1 . This was tested using the sibship $\times$ environment correlations in the two-environment ANOVAs; a significant interaction value indicates in the majority of cases that the cross-environmental correlation is $<+1$ (Fernando et al., 1984; Via and Conner, 1995) but this may not happen on all occasions and correlations not differing from +1 may occur with both a significant genotype term and a significant $G \times E$ interaction term (C. D. Schlichting, pers. comm.). All these variance component estimates come from a full-sib design; the estimated genetic correlation will contain contributions from common-environment effects and non-additive genetic variance (Falconer, 1989). We also estimated environmental correlations between size and time to metamorphosis for each sibship between mean responses of full-sib families at any particular combination of pond duration and density. Phenotypic correlations were estimated for each environment (among enclosures) using Pearson product-moment correlations.

\section{Results}

\section{Laboratory experiment}

Egg diameter ranged between $1.34-2.08 \mathrm{~mm}(x=1.66 \mathrm{~mm}, \mathrm{SD}=0.18 \mathrm{~mm}$, $N=50)$ and sibship identity was random with respect to egg size $\left(F_{4,45}=1.005\right.$, $P=0.415$ ). Larval survival probability was affected by density: (low density, $x=0.94, \mathrm{SD}=0.14$, high density, $x=0.77, \mathrm{SD}=0.12$, Tab. 1) but not affected by sibship main effect or sibship $x$ density interaction (Tab. 1). Size at metamorphosis decreased at high densities. Overall response of sibships did not differ with respect to mass at metamorphosis, but growth rate plasticity was genetically different (Tab. 1, Fig. 1B). Sibships 2 and 1 exhibited slight changes with larval density, but sibship 5 and 3 were very plastic (sibship 5 was the lightest at high density whereas at low density they attained the second largest size at metamorphosis). Time to metamorphosis was affected by sibship identity. Sibships 1 and 5 exhibited the fastest developmental rate, whereas sib 4 was the slowest developer (Tab. 1, Fig. 1A). Larval density significantly affected time to metamorphosis, delaying transformation at high density. However, no significant $G \times E$ interaction occurred, implying no genetic variability in the response to different larval densities (Tab. 1). 


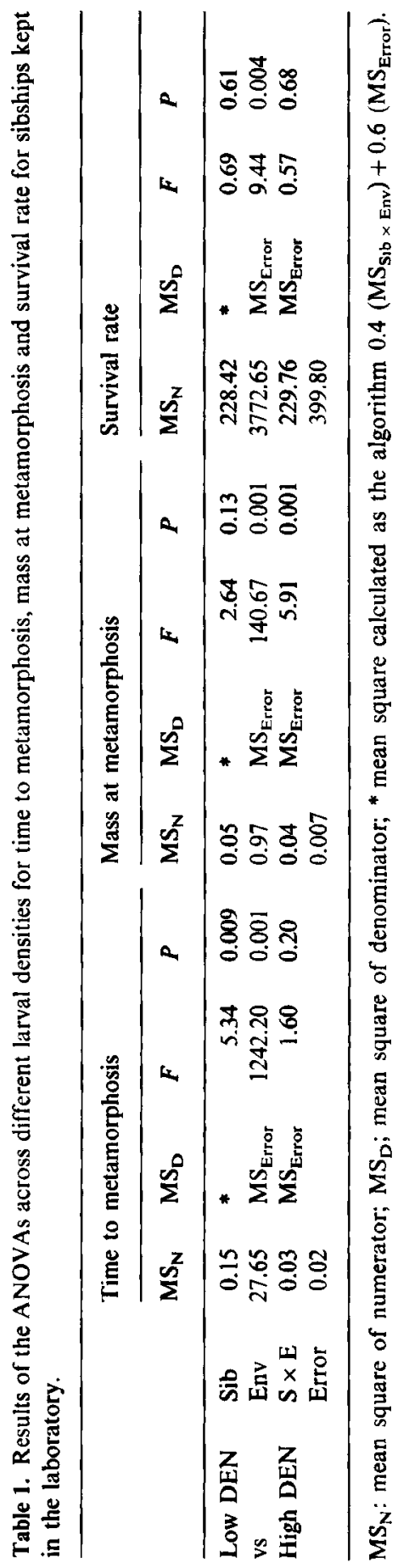




\section{Field experiment}

The temperature regimen was dependent on pond duration. Short duration ponds showed higher maximum temperatures than long duration ponds (paired $t$ test, $t=2.73, P=0.01, N=15$ ). However, minimum temperature did not vary between ponds of different duration $(t=0.57, P>0.05)$. Average temperature was also higher in short duration ponds $(t=2.40, P=0.023)$. A three-way MANOVA indicated that the multiple response of larval survival, rate of metamorphosis, time and mass to metamorphosis were significantly affected by sibship, larval density and pond duration (Tab. 2). The MANOVA also showed significant two-way interactions between sibship $\times$ density and sibship $\times$ duration and three-way interactions (Tab. 2).

In Table 3 univariate results of two-way ANOVAs testing how the response in metamorphosis is affected by sibship in combinations of two environments are shown. We established comparisons between five of the six potential environment combinations of pond duration and larval density; the exception was comparison of low and high density in long duration ponds due to the conclusion of the experiment. Larval survival was affected by pond duration at both densities,
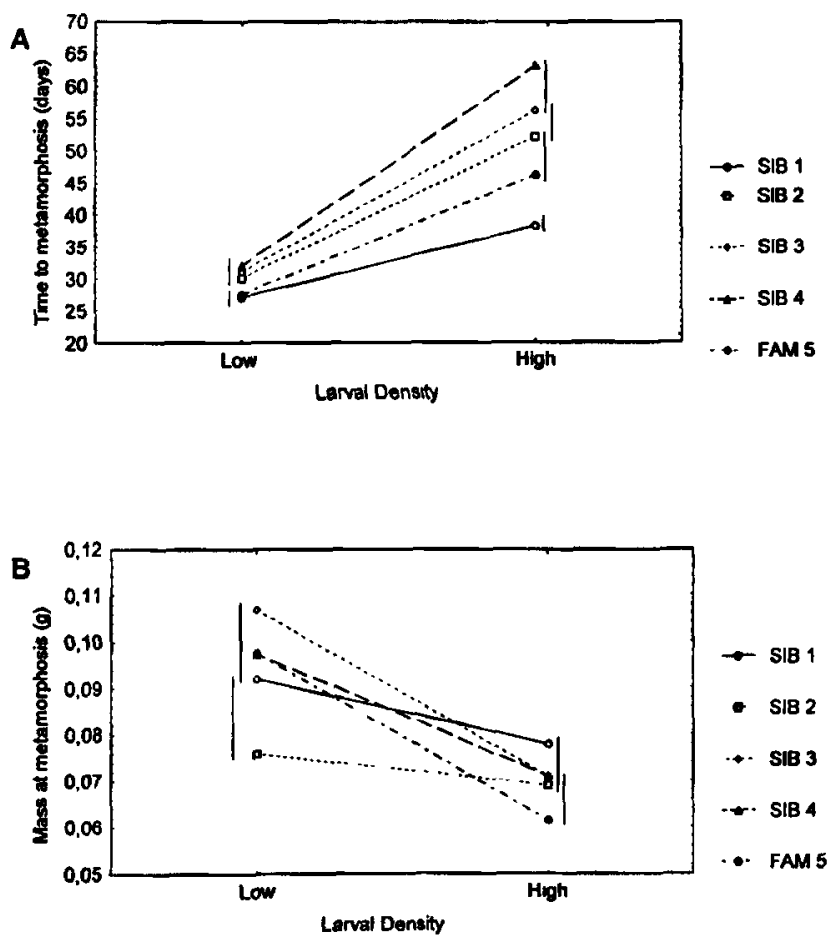

Fig. 1. Norms of reaction for mean date to metamorphosis and mean mass at metamorphosis, comparing performance in low and high larval density of five different sibships in the laboratory. Sibship means that are not different in a Tukey-Kramer HSD test $(P>0.05)$ are linked by vertical lines. 
Table 2. Summary of MANOVA for responses of Bufo calamita tadpoles to pond duration, larval density and sibship effect. Response variables were larval survival, percentage of survivors metamorphosing, body size at metamorphosis and days to metamorphosis.

\begin{tabular}{llcc}
\hline Source of variation & \multicolumn{2}{l}{ MANOVA } & P-value \\
\cline { 2 - 4 } & Wilk's $\lambda$ & df & $<0.00001$ \\
\hline Sibship & 0.035 & 16,67 & $<0.00001$ \\
Density & 0.007416 & 4,22 & 0.000124 \\
Duration & 0.365426 & 4,22 & $<0.00001$ \\
Sib $\times$ Den & 0.069156 & 16,67 & 0.000301 \\
Sib $\times$ Dur & 0.171875 & 16,67 & 0.745496 \\
Den $\times$ Dur & 0.918732 & 4,22 & 0.000035 \\
Sib $\times$ Den $\times$ Dur & 0.133826 & 16,67 & \\
\hline
\end{tabular}

showing lower mortality rates in long-lived ponds (Fig. 2A). Significant $G \times E$ interactions occurred at high density. All tadpoles that survived until the day of conclusion of the experiment reached metamorphosis at low larval densities (Fig. 2B). At high density, a significant $G \times E$ interaction arose, indicating that a decrease in pond durability did not determine an acceleration in development in all sibships determining differential mortality by pond desiccation.

Time to metamorphosis was not plastic in function of pond durability at low larval density. The rank of the different families was not altered in both environments; the fastest sibship 1 in short duration ponds also exhibiting highest developmental rates in long duration ones (Fig. 3). At high density, significant genetic variability for this plasticity was found (Tab. 3), indicating that sibship 1 decreased its developmental rates at long duration ponds whereas sibship 2,3 and $5 \mathrm{kept}$ it constant. Sibship 4 exhibited the longest time to metamorphosis in short ponds increasing significantly its mortality at metamorphosis. Time to metamorphosis was negatively correlated with the rate of metamorphosis in short duration ponds. This correlation was found both phenotypically (among different ponds $r=-0.826$ $P=0.002, N=11$ ) and genetically (mean-sibship, $r=0.908, P=0.033, N=5$ ). Faster developing sibships had a higher percent metamorphosis.

Overall mean mass at metamorphosis was not plastic in function of pond duration. Significant $G \times E$ was found at high larval density, implying that sibship 1 increased mass at metamorphosis in longer ponds (Fig. 4). Sibship 1 could gain differential size in longer ponds through its increase in age at metamorphosis and then simply because they have more time available for growth. However, when the duration of larval period was included as a convariate the differences between sibship 1 and the rest remained significant $\left(F_{4.5}=8.61, P=0.018\right.$, Tukey HSD sib $1>3=2=4=5$ ), therefore, sib 1 showed relatively higher growth rates than the other sibs. An increase in larval density determined a decrease in size at metamorphosis. Comparisons of environments with more contrasting actual larval density (low density-long duration pond vs. high density-short duration ponds) revealed a significant $G \times E$ where the rankings of genotypes shifted from heavier sibship 5 at 


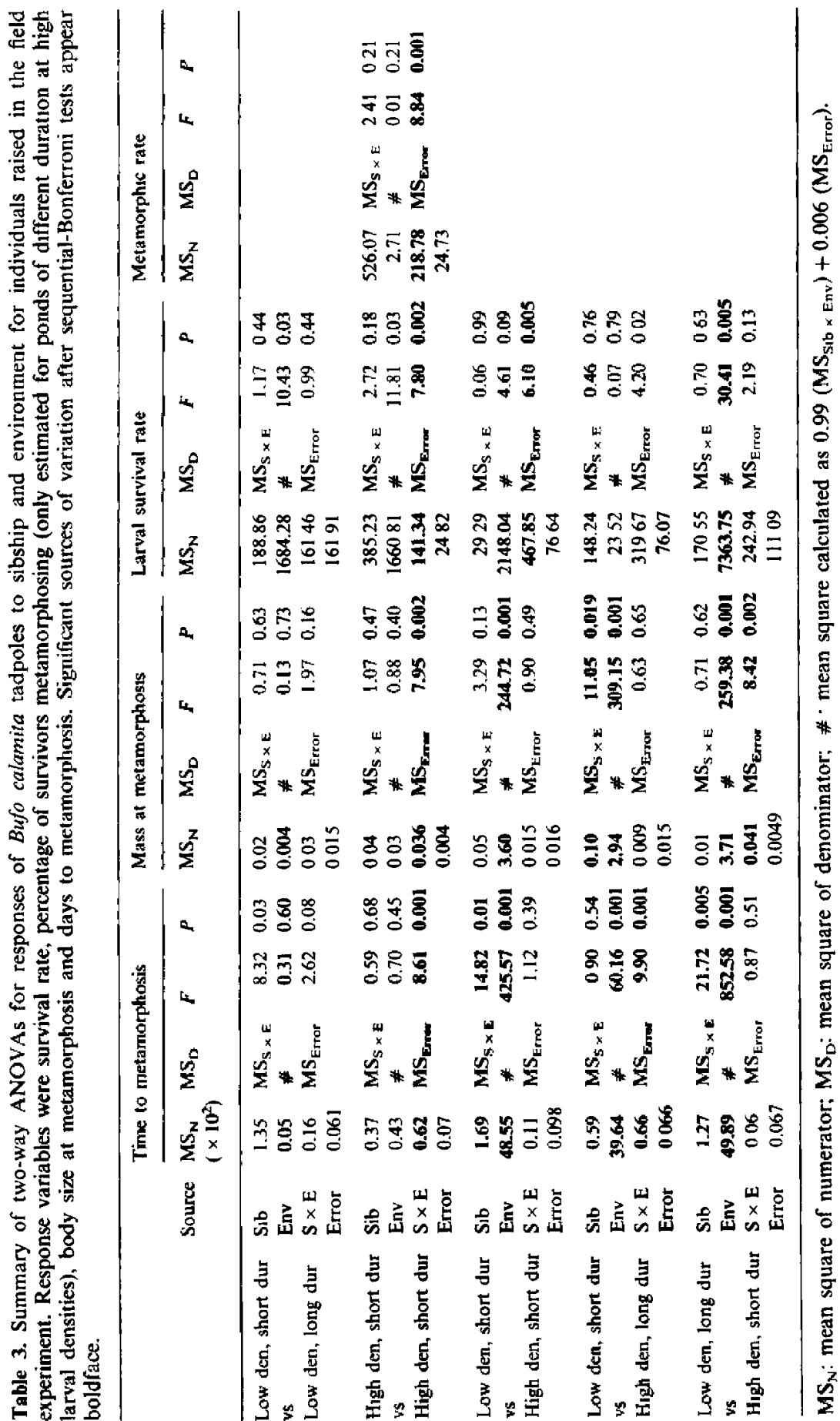


the lower density to sibship 2 at high density (Tab. 3, Fig. 4). The presence of genotype-environment interaction observed in metamorphic traits as a function of different larval densities and pond durations may both be attributed to genetic differences in environmental sensitivity $\left(V_{G \times E}\right)$ or, otherwise, related to specific sibship differences in larval survival or metamorphic rate, that strongly affect metamorphic traits by varying actual level of crowding conditions (Travis, $1983 \mathrm{a}, \mathrm{b})$. The results both for time and mass to metamorphosis were not altered by probability of larval survival when it was introduced in the model as a covariate (covariate effect, $P>0.20$ in all analyses). This indicated that genotypic differences in metamorphic traits did not correspond with different levels of sibship survival and reflect more their differences in susceptibility to competitive stress.
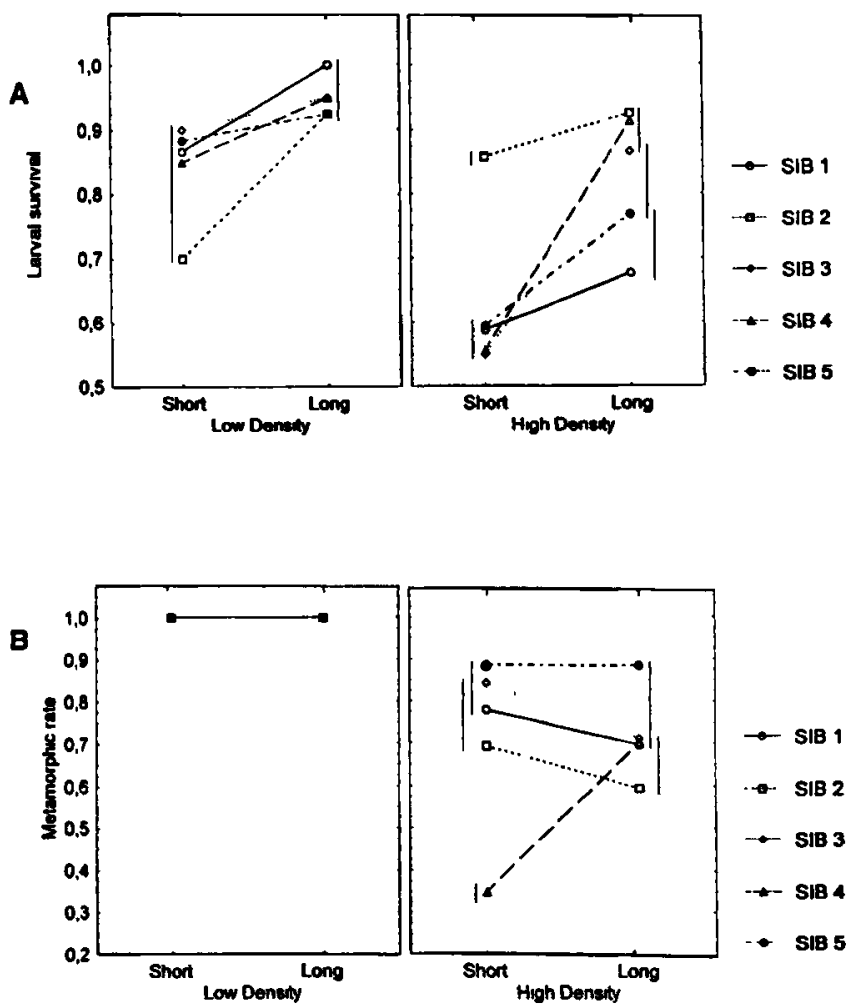

Fig. 2. Norms of reaction for: (A) mean larval survival proportions, comparing ponds of different duration at low and high larval densities; (B) mean percentage of survivors metamorphosing comparing ponds of different duration at low and high larval densities. Sibships means that are not different in a Tukey-Kramer HSD test $(P>0.05)$ are linked by vertical lines. 


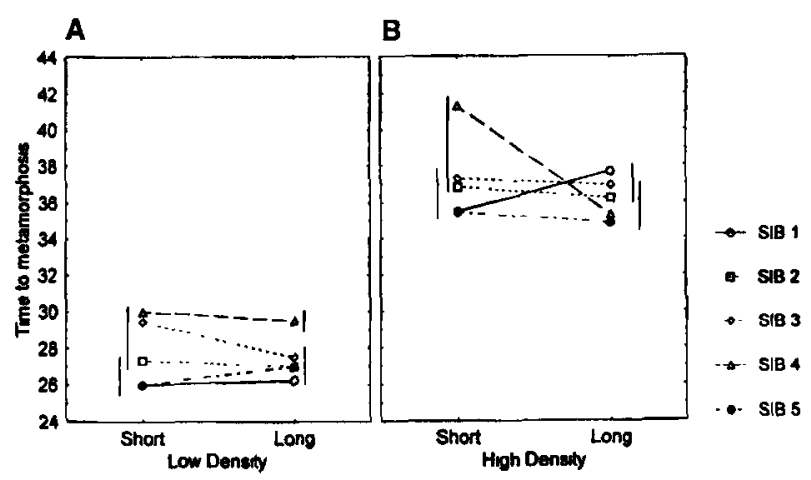

Fig. 3. Norms of reaction for mean date to metamorphosis, comparing performance in ponds of differing durations at low (A) and high (B) larval densities. Sibships means that are not different in a Tukey-Kramer HSD test $(P>0.05)$ are linked by vertical lines.

\section{Genetic and phenotypic correlations}

The values of the genetic correlations for each analysed combination of larval density and pond duration environment are shown in Table 4 . The existence of genetic correlations between character states affects the independence of the trait in the different environments, that is, constraining the potential for the evolution of optimal reaction norms (Via, 1987, 1994). Positive genetic correlations, different from zero were found for timing of metamorphosis at low larval densities in the field experiment between ponds of differing duration, thus suggesting that independent evolution of developmental rate is genetically constrained across pond durations. Results obtained in the laboratory were parallel to those obtained in the field; the value of the correlation does not differ from +1 either. Conversely, the order of sibships shifted across different pond durations at high larval density. Genetic correlations did not differ from 0 and independent evolution of time to metamorphosis is potentially possible. Mass at metamorphosis did not exhibit any significant genetic correlations in any pair-wise environmental comparison, with the exception of low-short, high-long environments, indicating that autonomous evolution of growth rates may occur in environments with different degrees of larval crowding. The genetic and phenotypic correlations between metamorphic traits for particular environments (Tab. 5) show that both traits were essentially uncorrelated at low density and could evolve independently but exhibited positive correlation especially for longer ponds which may constrain the separate evolution of both traits at high larval density.

\section{Juvenile growth and survival}

To ascertain the adaptiveness of the plastic response in larval growth rates and 


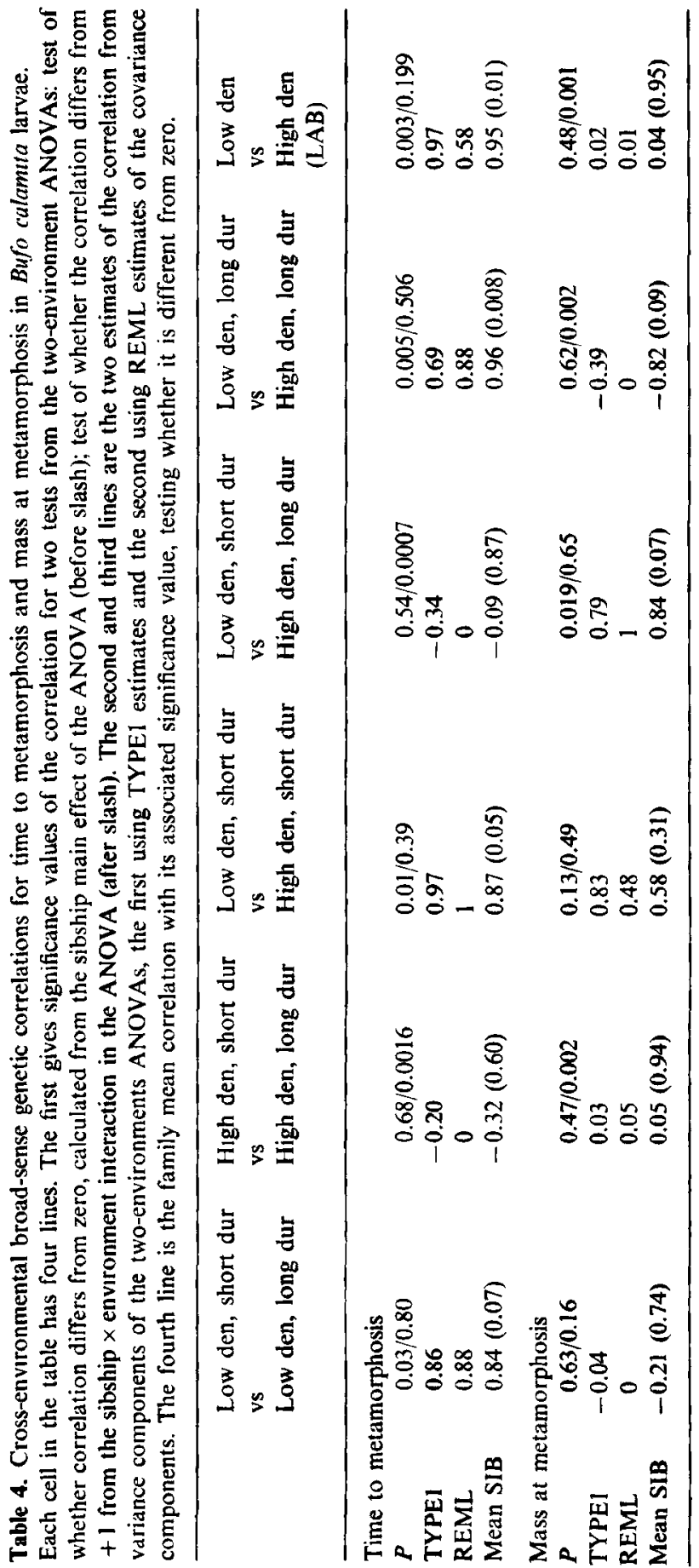



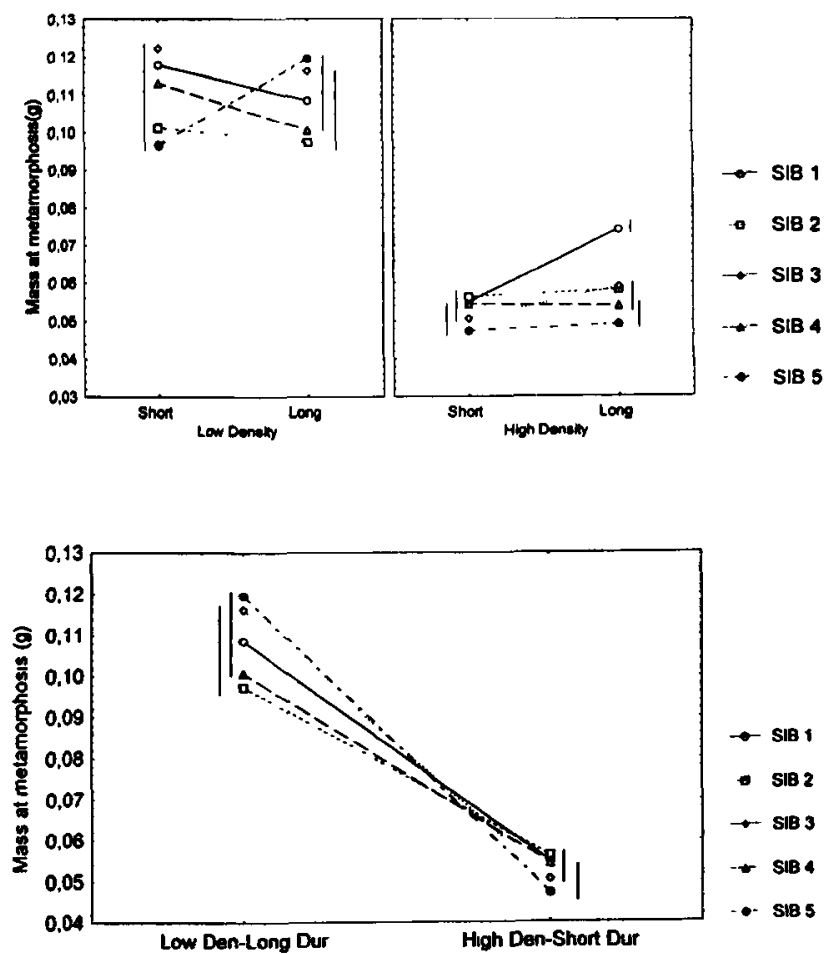

Fig. 4. Norms of reaction for mean mass at metamorphosis, comparing performance in ponds of differing durations at low and high larval densities and, comparing ponds of differing crowding conditions: low density-long duration pond vs high density-short duration ponds. Sibships means that are not different in a Tukey-Kramer HSD test $(P>0.05)$ are linked by vertical lines.

fitness effect of metamorphic size, we studied juvenile growth and survival of the same five sibships born in ponds of high larval density. Initial size at metamorphosis affected juvenile survival. After one month, the initial size of survivors was larger $(x=0.069 \pm 0.011 \mathrm{~g}, N=18)$ than that of those that died during that period

Table 5. Genetic (family mean estimate) and phenotypic correlations between time to metamorphosis and size at metamorphosis of Bufo calamita larvae within each environmental combination of pond durations and larval density.

\begin{tabular}{lrr}
\hline & Family mean & \multicolumn{1}{c}{ Phenotypic } \\
\hline Low den, short dur & $0.05(0.94)$ & $0.04(0.89) N=12$ \\
High den, short dur & $0.49(0.39)$ & $0.30(0.36) N=11$ \\
Low den, long dur & $-0.19(0.76)$ & $0.16(0.63) N=11$ \\
High den, long dur & $0.89(0.04)$ & $0.77(0.006) N=11$ \\
Low den (laboratory) & $0.01(0.99)$ & $-0.07(0.76) N=20$ \\
High den (laboratory) & $0.14(0.82)$ & $-0.06(0.81) N=20$ \\
\hline
\end{tabular}

In parentheses are probability values associated to each correlation coefficient. 


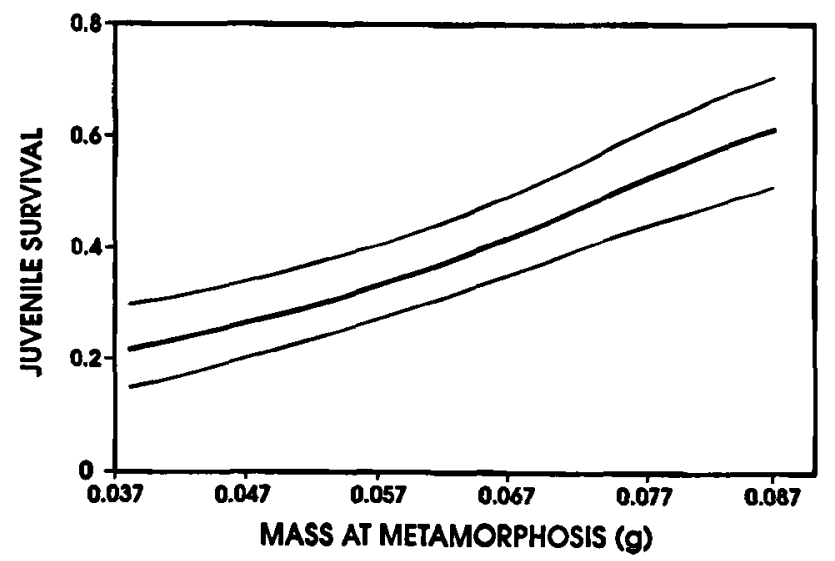

Fig. 5. Univariate selection surface for metamorph size estimated using the cubic-spline (Schluter, 1988). Standard errors for the spline was calculated by bootstrapping the original data 100 times. Size range examined corresponded to individuals born at high density ponds.

$\left(x=0.053 \pm 0.009 \mathrm{~g}, N=32, F_{1,48}=29.655, P=0.0001\right)$. Moreover, the number of days of survival in the latter group was positively correlated with initial size $\left(r=0.444, F_{1.26}=6.382, P=0.017\right)$. Sibship 1, with the heaviest metamorphic size, had $90 \%$ survival whereas lighter metamorphs of sibship 5 only experienced $10 \%$ survival. The non-parametric fitness function of survival on metamorphic size revealed a monotonic relationship between both variables (Fig. 5). We also tested whether growth rate during the terrestrial phase was kept uniform or contrarily modified with respect to growth during the larval phase. Growth rate for those individuals that survived was not different among sibships $\left(F_{4,13}=1.03, P=0.43\right)$. Juvenile size on day 30 after the start of experiment was different among families $\left(F_{4,13}=3.09, P=0.05\right)$. However, these differences are the expression of initial differences in size of sibships at the start of the experiment. Once initial size of juveniles was taken as a covariate, the sibship effect disappeared $\left(F_{4.12}=1.78\right.$, $P=0.21$ ).

\section{Discussion}

The amount of genetic variability in the level of plasticity of time of larval development to differing hydroperiods was a function of larval density in the natterjack tadpole population. At low larval density no significant $G \times E$ interaction was found and genetic correlations between different pond durations were different from zero and even equal to +1 , both in the field and in the laboratory. This suggests that the contribution of changes in genotypic ranking was minimal and the degree of genetic dependence in both environments at the maximum, which may impose a constraint on the separate evolution of developmental rates in both pond environments. This scenario changes at high larval density, sibships showing 
variability in the response to hydroperiod duration as indicated by the presence of $G \times E$ interactions. Significant interaction variance is a necessary prerequisite for the evolution of a plastic reaction norm. However, the amount of variance due to $G \times E$ is not directly related to the level of genetic independence (Via and Lande, 1985; Via 1987). $G \times E$ variance could arise for two reasons, one being that genetic variances in the two environments are different and the other being a lack of perfect correlation of the genetic effects in the different environments (Cockerham, 1963; Tachida and Mukai, 1985). A lack of correlation between the genetic effects in both environments (e.g., when genetic correlation did not differ from zero) occurs when there are reversals of fitness order as shown by sibship 1 having the shortest time of development at short pond durations but the longest at longer ponds.

To identify adaptive plasticity we have to determine the effect on fitness of a particular reaction norm relative to other norms including non-plastic phenotypes (Newman, 1992). Sibship 1, by adopting a plastic reaction norm at high larval density, had the highest metamorphic survival in short duration ponds and the largest size at transformation in long duration ponds. The plastic reaction norm of sibship 4 appeared to be maladaptive since developmental rate decreased at short duration ponds, which indicated differential higher metamorphic mortality. Sibship 2, 3 and 5, exhibited high developmental rates obtaining an advantage in metamorphic survival in short duration ponds but their non-plastic reaction norms render them unable to increase metamorphic size in longer ones. Theory predicts that when an optimal level of plasticity is attained at equilibrium, genetic variation for plasticity will be exhausted (Via and Lande, 1985). This expected output was found for Scaphiopus couchii where no genetic variance for plasticity was found for timing to metamorphosis because of its positive correlation with fitness (Newman, 1988). If selection were to favour an optimal reaction norm such as apparently displayed by sibship 1, we would expect non-plastic or maladaptive reaction norms to be wiped out of the Toba population and $G \times E$ interaction variance to be depleted. However, the significant amount of genetic variance in plasticity observed may be the response to the fact that the evolution of the norm of reaction is still in progress and relatively not proximate to the optimal reaction norm at equilibrium (Via and Lande, 1985). An alternative would be that the specialization of genotypes to separate larval microhabitats promotes genetic variation for plasticity (the Levene's model of the specialization of genotypes to separate microhabitats, Levene, 1953). However, this explanation would imply local population regulation in each microhabitat type, which seems unlikely due to the sufficient re-mixing of the genotypes over the whole environment that occurs in every generation. An important deterrent for the evolution of an optimum reaction norm is when there is a cost to the plasticity (van Tienderen, 1991). The cost of plasticity may be regarded as the effect that a particular selected trait has on the expression of other traits and the consequent implications for fitness (Newman, 1992). In amphibians, a slower developmental rate in longer, more promising ponds, may have the advantage of bigger size at metamorphosis; however, when relative benefits in growth and survival are higher in the terrestrial than in the aquatic stage, transformation would proceed because lingering in the pond may be relatively costly (Werner, 1986). 
Toadlets found close to a breeding pond weighed on average $1.1 \mathrm{~g}(N=120)$ one month after the first metamorph appeared. This represents around 30 times the growth rate experienced during the larval stage (unpublished data). Similar rapid post-metamorphic growth rates are common in other bufonids (e.g., Clarke, 1974).

Significant $G \times E$ interaction in size at metamorphosis between ponds that differed in larval density level reflected the potential for specialization to different crowding conditions in the Toba natterjack population. Sibship 5 exhibited higher growth rates at lower crowding conditions whereas sibship 2 showed lower rates. This situation reversed at the more severe environment of high density ponds, sibship 2 being bigger at metamorphosis than sibship 5, although its higher larval survival implied a harder competitive environment for this sibship. The rate of evolution of the reaction norm will necessarily depend both on the genetic variance within environments in combination with the degree of independence of the character states expressed in the different environments, and on the non-existence of genetic trade-offs with other traits that affect fitness (Via and Lande, 1985). Size at metamorphosis showed significant genetic variance within each environment and character states showed genetic independence. In addition, no genetic correlations between size and age at metamorphosis suggest the independent trajectory of both traits within environments.

To examine the fitness implications of observed genetic variability for plasticity in growth rates, we need to evaluate the ecological relevance of the trait on fitness and know the relative frequency of the environments (Via and Lande, 1985; Endler, 1986; Via, 1987). Size at metamorphosis is positively related to survival. Selection surface revealed that juvenile survival was a monotonic function of metamorphic size in individuals raised at high larval densities. Those sibships that gain a differential metamorphic size have a major probability of survival during the early terrestrial phase. Because juvenile growth rates did not exhibit genetic variability no possible correlation between both rates was expected, and sibships with relatively higher metamorphic size maintained their rank, at least under the experimental conditions one month after metamorphosis. This lack of correspondence between larval and juvenile growth rates was also found by Blouin $(1989,1992)$ in two hylids and may support the adaptive decoupling hypothesis for species with complex life cycles (Moran, 1994), that predicts free evolution and no pleiotropic constraints between life stages. In amphibians, larger size at transformation may be highly adaptive in the terrestrial habitat as has been demonstrated in other amphibians through an increase in survival, fecundity or early sexual maturation (Smith, 1987; Semlitsch et al., 1988; Berven, 1990; Pfennig et al., 1991; Scott, 1994), or higher physiological performance of larger metamorphs (Taigen and Pough, 1981; Pough and Kamel, 1984; John-Alder and Morin, 1990; Goater et al., 1993; Newman and Dunham, 1994; Tejedo et al., submitted) that may affect lifetime reproductive success. The presence of genetic plasticity in growth rates and then $G \times E$ interactions may be highly adaptive because it may contribute to the maintenance of quantitative genetic variation for fitness related traits (Via and Lande, 1987; Gillespie and Turelli, 1989). $G \times E$ interactions can ameliorate the correlation between genotype and phenotype and the ability of selection to discrim- 
inate among genotypes may be drastically weakened. Natterjack tadpoles exhibit extreme differences in yearly average larval density, increasing or decreasing eight-fold from one season to another (Tejedo and Reques, 1994) and even more within different pools in the breeding area (Tejedo, 1992a). Moreover, spatial heterogeneity in relation to both larval densities and pond hydroperiods exists, indicating that in wetter years very shallow, small ponds, sometimes $<1 \mathrm{~m}^{2}$, are flooded around Toba main pond. In these flooded areas numerous clutches are laid drastically increasing the actual level of larval density in spite of the impermanence of these habitats (Tejedo, 1992a). In addition, natterjacks exhibit a protracted breeding pattern with several bursts of spawning during the breeding season (Tejedo, 1992b). In this sense, both pond density and duration may vary extensively on a temporal or spatial scale, indicating multiple environmental heterogeneity.

In conclusion, there appears to be no plastic response in developmental rates as a function of pond durability at low larval density, and significant genetic variability for this plasticity at high density. At low density, genetic constraints may limit the evolution of reaction norm, and we hypothesized that the expressed genetic variability for plasticity to capitalize in growth at high density may be neutral with respect to selection, because most selective action affecting growth may certainly occur during the terrestrial phase. Secondly, significant adaptive plasticity for growth rates appears in environments that differ drastically in level of crowding conditions, thus accounting for the maintenance of genetic variability in highly heterogeneous larval environments. Further research on organisms such as amphibians with complex life cycles should focus on the role of $G \times E$ interactions between differing terrestrial environments and also between larval and terrestrial environments to disclose the potential for independent evolution and the existence of trade-offs between the aquatic and terrestrial phases.

\section{Acknowledgements}

We thank L. M. Carrascal, R. Fraga, J. Moreno, J. Potti, C. D. Schlichting and one anonymous referee whose comments improved the manuscript. P. Jordano and S. Reig provided statistical advice. We would also like to thank the family Gutierrez Escobar for allowing us to use their property to locate the artificial ponds. Thanks are due to L. Arias de Reyna and M. Ferreras for access to and use of the facilities in the Facultad de Ciencias de Córdoba; also to S. Carpintero for her field assistance. This work was partially supported by Convenio CSIC-ICONA, "Alytes en las sierras Béticas" and by postdoctoral grants of the Ministerio de Educación y Ciencia y convenio CSIC-CAM to MT.

\section{References}

Ayres, M. P. and D. L. Thomas. 1990. Alternative formulations of the mixed-model Anova applied to quantitative genetics. Evolution 44: 221-226. 
Banks, B. and T. J. C. Beebee. 1988. Reproductive success of natterjack toads Bufo calamita in two contrasting habitats. Journal of Animal Ecology 57: 475-492.

Berven, K. A. 1990. Factors affecting population fluctuations in larval and adult stages of the wood frog (Rana sylvatica). Ecology 71: 1599-1608.

Blouin, M. S. 1989. Life history correlates of a color polymorphism in the ornate chorus frog, Pseudacris ornata. Copeia 1989: 319-325.

Blouin, M. S. 1992. Genetic correlations among morphometric traits and rates of growth and differentiation in the green tree frog, Hyla cinerea. Evolution 46: 735-744.

Clarke, R. D. 1974. Postmetamorphic growth rates in a natural population of Fowler's toad, Bufo woodhousei fowleri. Canadian Journal of Zoology 52: 1489-1498.

Cockerham, C. C. 1963. Estimation of genetic variances, pp 53-94. In W. D. Hanson and H. F. Robinson (Eds.), Statistical Genetics and Plant Breeding. National Research Council, Publication 982, Washington, D. C., U.S.A.

Endler, J. A. 1986. Natural Selection in the Wild. Princeton University Press, Princeton, N.J., U.S.A.

Falconer, D. S. 1952. The problem of environment and selection. Am. Nat. 86: 293-298.

Falconer, D. S. 1989. Introduction to Quantitative Genetics, 3rd ed. Longman Scientific and Technical, Harlow, UK.

Fernando, R. L., S. A. Knights and D. Gianola. 1984. On a method of estimating the genetic correlation between characters measured in different experimental units. Theor. Appl. Genet. 67: 175-178.

Fry, J. D. 1992. The mixed-model analysis of variance applied to quantitative genetics: biological meaning of the parameters. Evolution 46: 540-550.

Gillespie, J. H. and M. Turelli. 1989. Genotype-environment interactions and the maintenance of polygenic variation. Genetics 121: 129-138.

Goater, C. P., R. D. Semlitsch and M. V. Bernasconi. 1993. Effects of body size and parasite infection on the locomotory performance of juvenile toads, Bufo bufo. Oikos 66: 129-136.

Gomulkiewicz, R. and M. Kirkpatrick. 1992. Quantitative genetics and the evolution of reaction norms. Evolution 46: 390-411.

Gosner, K. L. 1960. A simplified table for staging anuran embryos and larvae with notes on identification. Herpetologica 16: 183-190.

Hurlbert, S. H. 1984. Pseudoreplication and the design of ecological field experiments. Ecological Monographs 54: 187-211.

John-Alder, H. B. and P. J. Morin. 1990. Effects of larval density on jumping ability and stamina in newly metamorphosed Bufo woodhousei. Copeia 1990: 856-860.

Levene, H. 1953. Genetic equilibrium when more than one ecological niche is available. American Naturalist 87: $311-313$.

Mazer, S. J. and C. T. Schick. 1991. Constancy of population parameters for life history and floral traits in Raphanus sativus L. I. Norms of reaction and the nature of genotype by environment interactions. Heredity 67 : 143-156.

Moran, N. A. 1994. Adaptation and constraint in the complex life cycles of animals. Ann. Rev. Ecol. Syst. 25: 573-600.

Newman, R. A. 1988. Adaptive plasticity in development of Scaphiopus couchii tadpoles in desert ponds. Evolution 42: 774-783.

Newman, R. A. 1989. Developmental plasticity of Scaphiopus couchii tadpoles in an unpredictable environment. Ecology 70: 1775-1787.

Newman, R. A. 1992. Adaptive plasticity in amphibian metamorphosis. Bioscience 42: 671-678.

Newman, R. A. 1994a. Genetic variation for phenotypic plasticity in the larval life history of spadefoot toads (Scaphiopus couchii). Evolution 48: 1773-1785.

Newman, R. A. 1994b. Effects of changing density and food level on metamorphosis of a desert amphibian, Scaphiopus couchii. Ecology 75: 1085-1096.

Newman, R. A. and A. E. Dunham. 1994. Size at metamorphosis and water loss in a desert anuran (Scaphiopus couchii). Copeia 1994: 372-381. 
Pechmann, J. H. K., D. E. Scott, R. D. Semlitsch, J. P. Caldwell, L. J. Vitt and J. W. Gibbons. 1991. Declining amphibian populations: The problem of separating human impacts from natural fluctuations. Science 253: 892-895.

Pfennig, D. W., A. Mabry and D. Orange. 1991. Environmental causes of correlations between age and size at metamorphosis in Scaphiopus multipltcatus. Ecology 72: 2240-2248.

Pough, F. H. and S. Kamel. 1984. Post-metamorphic change in activity metabolism of anurans in relation to life history. Oecologia 65 : $138-144$.

Rausher, M. D. 1984. Tradeoffs in performance on different hosts: Evidence from within- and between-site variation in the beetle Deloyala guttata. Evoution 38: 582-595.

SAS Institute, Inc. 1990. SAS/STAT User's Guide, Version 6, 4th edn. Volume 2. SAS Institute Inc. 846 pp Cary, N.C., U.S.A.

Scheiner, S. M. 1993. Genetics and evolution of phenotypic plasticity. Annu. Rev. Ecol. Syst. 24: 35-68.

Scheiner, S. M. and C. J. Goodnight. 1984. The comparison of phenotypic plasticity and genetic variation in populations of the grass Danthonia spicata Evoution 38: 845-855.

Schluter, D. 1988. Estimating the form of natural selection on a quantitative trait. Evoution 42: 849-861.

Scott, D. E. 1994. The effect of larval density on adult demographic traits in Ambystoma opacum. Evoution 75: 1383-1396.

Semlitsch, R. D. 1993. Adaptive genetic variation in growth and development of tadpoles of the hybridogenetic Rana esculenta complex. Evoution 47: 1805-1818.

Semlitsch, R. D., D. E. Scott and J. H. K. Pechmann. 1988. Time and size at metamorphosis related to adult fitness in Ambystoma talpoideum. Ecology 69: 184-192.

Semlitsch, R. D. and H. M. Wilbur. 1988. Effect of pond drying time on metamorphosis and survival in the salamander Ambystoma talpoideum. Copeia 1988: 978-983.

Semlitsch, R. D. and H. U. Reyer. 1992. Performance of tadpoles from the hybridogenetic Rana esculenta complex: interactions with pond drying and interspecific competition. Evolution 46: 665-676.

Shaw, R. G. 1986. Response to density in a wild population of the perennial herb Salvia lyrata: variation among families. Evolution 40: 492-505.

Shoop, C. R. 1974. Yearly variation in larval survival of Ambystoma maculatum. Ecology 55: 440-444.

Sinsch, U. 1992. Structure and dynamic of a natterjack toad metapopulation (Bufo calamita). Oecologia 90: $489-499$.

Schlichting, C. D. 1986. The evolution of phenotypic plasticity in plants. Annual Review of Ecology and Systematics 17: 667-693.

Smith, D. C. 1983. Factors controlling tadpole populations on the chorus frog (Pseudacris triseriata) on Isle Royale. Ecology 64: 501-510.

Smith, D. C. 1987. Adult recruitment in chorus frogs: effects of size and date at metamorphosis. Ecology 68: $344-350$.

Stearns, S. C. and J. C. Koella. 1986. The evolution of phenotypic plasticity in life-history tratts: predictions of reaction norms for age and size at maturity. Evolution 40: 893-913.

Tachida, H. and T. Mukai. 1985. The genetic structure of natural populations of Drosophila melanogaster. XIX. Genotype-environment interaction in viability. Genetics 111: 43-55.

Taigen, T. L. and F. H. Pough. 1981. Activity metabolism of the toad (Bufo americanus): ecological consequences of ontogenetic change. Journal Comparative Physiology B 144: 247-252.

Tejedo, M. 1992a. Effects of body size and tuming of reproduction on reproductive success in female natterjack toads (Bufo calamita). Journal of Zoology 228: 545-555.

Tejedo, M. 1992b. Large male mating advantage in natterjack toads, Bufo calamira: sexual selection or energetic constraints? Anim. Behav. 44: $556-569$.

Tejedo, M. and R. Reques. 1994. Plasticity in metamorphic traits of natterjack tadpoles. The interactive effects of density and pond duration. Oikos 71: 295-304.

Thomas, S. C. and F. A. Bazzaz. 1993. The genetic component in plant size hierarchies: norms of reaction to density in a Polygonum species. Ecol. Monogr. 63: 231-249.

Travis, J. 1980. Phenotypic variation and the outcome of interspecific competition in hylid tadpoles. Evolution 34: $40-50$. 
Travis, J. 1983a. Variation in development patterns of larval anurans in temporary ponds. Y. Persistent variation within a Hyla gratiosa population. Evolution 37: 496-512.

Travis, J. 1983b. Variation in growth and survival of Hyla gratıosa larvae in experimental enclosures. Copeia 1983: 232-237.

Travis, J. 1994. Evaluating the adaptive role of morphological plasticity, pp 99-122. In P. C. Wainwright and S. Reilly (Eds), Ecomorphology: Integrative Organismal Biology. University of Chicago Press, Chicago. U.S.A.

van Tienderen, P. H. 1991. Evolution of generalists and specialists in spatially heterogeneous environments. Evolution 45: 1317-1331.

Via, S. 1984. The quantitative genetics of polyphagy in an insect herbivore. II. Genetic correlations in larval performance within and across host plants. Evolution 38: 896-905.

$\mathrm{Via}, \mathrm{S}$. 1987. Genetic constraints on the evolution of phenotypic plasticity, pp 47-71. In V. Loeschcke (Ed.), Genetic Constraints on Adaptive Evolution. Springer-Verlag, Berlin. Germany.

Via, S. 1994. The evolution of phenotypic plasticity: what do we really know?, pp 35-57. In L. A. Real (Ed.), Ecological Genetics, Princeton University Press, Princeton, U.S.A.

$\mathrm{Via}$, S. and R. Lande 1985. Genotype-environment interaction and the evolution of phenotypic plasticity. Evolution 39: 505-522.

Via, S. and R. Lande 1987. Evolution of genetic variability in a spatially heterogeneous environment: effects of genotype-environment interaction. Genet. Res., Camb. 49: 147-156.

Via, S. and J. Conner. 1995. Evolution in heterogeneous environments: genetic variability within and across different grains in Tribolium castaneum. Heredity 74: 80-90.

Via, S., R. Gomulkiewicz, G. de Jong, S. M. Scheiner, C. D. Schlichting and P. H. van Tienderen. 1995. Adaptive phenotypic plasticity: consensus and controversy. Tree 10: 212-217.

Werner, E. E. 1986. Amphibian metamorphosis: growth rate, predation risk, and the optimal size at transformation. American Naturalist 128: 319-341.

Wilbur, H. M. 1980. Complex life cycle. Annual Review of Ecology and Systematics 11: 67-93.

Wilbur, H. M. 1987. Regulation of structure in complex systems: experimental temporary pond communities. Ecology 68: 1437-1452.

Wilbur, H. M. and J. P. Collins. 1973. Ecological aspects of amphibian metamorphosis. Science 182: $1305-1314$.

Yamada, Y. 1962. Genotype $\times$ environment interaction and genetic correlation of the same trait under different environments. Jap. J. Genet. 37: 498-509.

Received 21 August 1996; revised 20 December 1996; accepted 31 January 1997. 